\title{
SAILING ROUTE PLANNING METHOD CONSIDERING VARIOUS USER CATEGORIES
}

\begin{abstract}
The article describes the methodology related to determining the multi-criteria routes for sailing ships. Details of sea area discretisation and discretisation of the description of the sailing vessel properties and manoeuvring principles are shown. User requirements were specified (for five different categories of users) and on this basis the criteria for selecting the most suitable shipping route were formulated. The presented algorithm recommends a route for a given user category by means of defined restrictions and configuration parameters. The applied multi-criteria approach proves the universality and usability of the sailing ship route planning method.
\end{abstract}

Keywords: sailing vessel,weather routing,multi-criteria,navigation,comfort

\section{INTRODUCTION}

The planning of routes in maritime transport inspired scientists as early as the era when sailing vessels were still the only means of transport enabling ocean travel. The first attempts at sailing vessel route recommendations (least-time tracks based on statistical wind and current data) were made by Maury 7 in the 19 th century. In the 20 th century, powerdriven ships became the main means of maritime transport. In turn, sailing vessels have changed their role in transport from cargo ships to vessels used in regattas and for tourism. Initially, after this change of role, sailing vessels lost their importance in transport. It should be emphasised, however, that cultural changes in the face of commercialisation have strongly influenced the development of urban tourism 16.This has also increased interest in cruise ships, and as a result also influenced the specificity and role of sailing. What is more, regattas and extreme cruises have become very popular. In recent years, during large commercial regattas, the border between sport and passenger transport has been blurred, becoming understood as a paid transport service. The crew consists of both professional and amateur sailors, i.e. paying participants (partly with the rights of "passengers"). This allows regatta organisers to obtain additional financial benefits, and "passengers" seeking extreme sensations are provided with experiences that they would not experience on a typical tourist ship.

An important role in sailing is played by the speed of the sailing vessel, so it is important to know the speed characteristics of the ship. These are closely related to the technical parameters of the ship, and can be obtained using appropriate software (for example, the commercial Bentley 
Systems package). The use of such characteristics is crucial during regattas. However, the role of speed characteristics in recreational and tourist shipping should also be emphasised. The possibility of setting a relatively fast route may have an impact on the safety of the often small ship, its crew and passengers. Effective planning of a route to the harbour of refuge in the event of deteriorating weather conditions is an important issue 3. Security issues are extremely important. This also applies to autonomous sailboats 15 . This subject is discussed at the annual International Robotic Sailing Conference (IRSC), which also emphasises the importance of this issue. The purpose of this article is to present a multicriteria method for determining the route of a sailing vessel from the starting point to the final point, taking into account hydrometeorological data and various travel criteria. The universality and usability of the method were shown through the categories of users under consideration with different preferences. They were defined by criteria and restrictions that take into account the requirements of both regatta and recreational ship users seeking extreme sensations, as well as beginner sailors and unmanned sailing ships.

The article is a continuation of the author's research on determining routefor sailing vessels. In the previous stages of the author's work, the discrete research environment consisted of 3528 points (navigable and non-navigable) and discreetly defined the area of the Gulf of Gdańsk 17-20. The current research environment has been increased to $14,523,121$ available points, which makes it possible to cover the discrete research area of the Baltic Sea area to a latitude of $57^{\circ} \mathrm{N}$.

\section{RELATED WORKS}

Route planning methods in shipping can be divided into two groups depending on the approach used. The first group are deterministic methods that give the same solution for the same input data 2,6,8,13,4,1time and space complexity, search space auto-adaptation properties. This solution does not take into account the order and time factor in the introduction of preliminary assumptions. Tasks carried out on the same input data obtain repeatable calculations. Updating the input data or changing the initial assumptions can lead to a different solution.

The second group are non-deterministic methods that take into account issues that would be too time-consuming for deterministic methods $10-12,9,5,14$. These concern oceanic routes, which take into account the many variants of weather forecasts, as well as the avoidance of tropical cyclones in ocean navigation or anti-collision manoeuvres. Non-deterministic methods consider more complex phenomena with more input data than deterministic methods. However, nondeterministic methods reduce the range of input data using random phenomena, which means that the final result is an approximate value.

The route calculation method presented in this article is for parts of the southern Baltic Sea. Due to the fact that the research area is not very large, the presented method uses a deterministic approach. However, it is necessary to implement this method based on 64-bit architecture.

\section{SAILING ROUTE PLANNING METHODS}

The task of the presented method is to recommend a route within the permissible sailing area for a specific user, taking into account his requirements and restrictions resulting from safety requirements. The task formulated in this way requires consideration of the most likely route selection options under the conditions prevailing in the given navigation area. Further, an adequate description of the ship's properties and user requirements is important. Fig. 1 shows the information flow needed to perform this analysis. In addition to the description of the navigation space, presentation of the conditions in this space, the ship properties and user requirements, appropriate route calculation algorithms as well as supporting procedures are necessary. Besides, due to the possible dynamics of changes in the navigable area in question, it is necessary to know current external data on hydrometeorological changes. Due to the nature of the phenomena described and the complexity of aerodynamic and hydrodynamic problems, an appropriate and effective modelling method is also required, which requires the use of various types of software, including appropriate IT services.

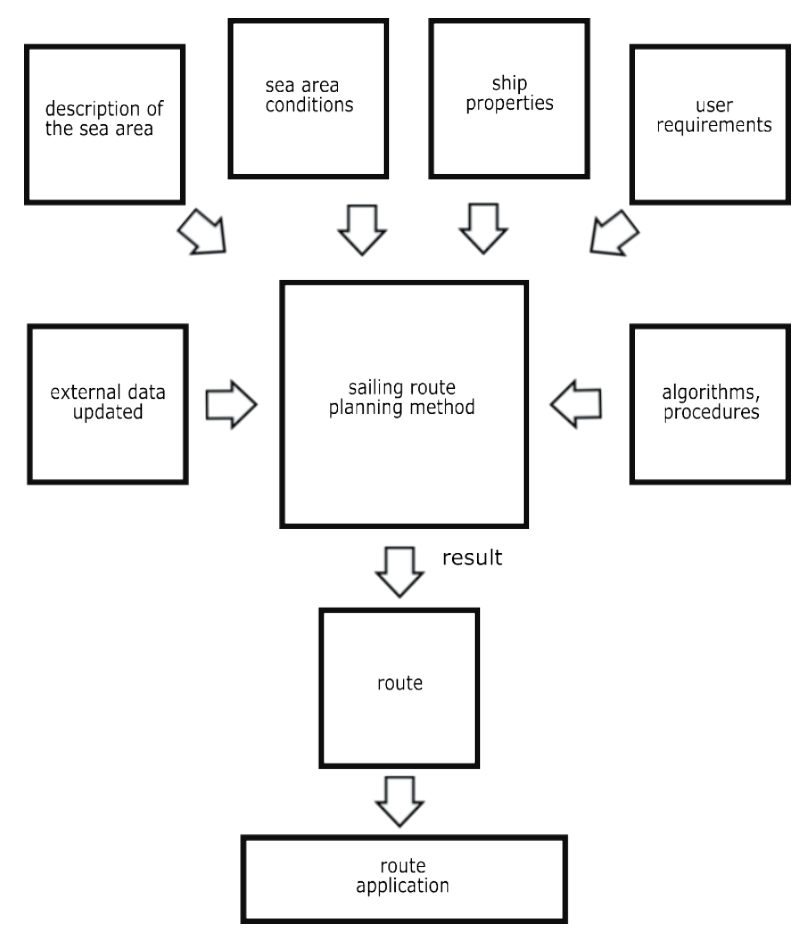

Fig. 1. Information flow in the sailing vessel route planning method

This means the need to map the real world through the digital environment, as well as to develop an appropriate work methodology. It consists of the following activities:

- Discretisation of the navigable area 
- Discretisation of the description of the sailing vessel properties and manoeuvring rules

- Specifying user requirements and, on this basis, formulating criteria for selecting the most suitable shipping route.

- Development of an algorithm of multi-criteria selection of the most suitable route.

The above activities will be discussed in more detail in the following sections.

\section{NAVIGATION AREA DISCRETISATION}

In the described method, the marine environment was limited to a finite discrete sea area. The variable parameters of the sailing vessel movement were: geographical position, ship course, ship speed, course change speed.

In turn, a limited area of the marine environment is designated on the globe by coastal parallels and meridians $\left(\varphi_{1}, \varphi_{m}, \lambda_{1}, \lambda_{n}\right)$. Fig. 2 shows a simplified section of the marine environment, where land is marked in grey and sea is marked in white. In practice, it can take various shapes resulting from a given geographical area.

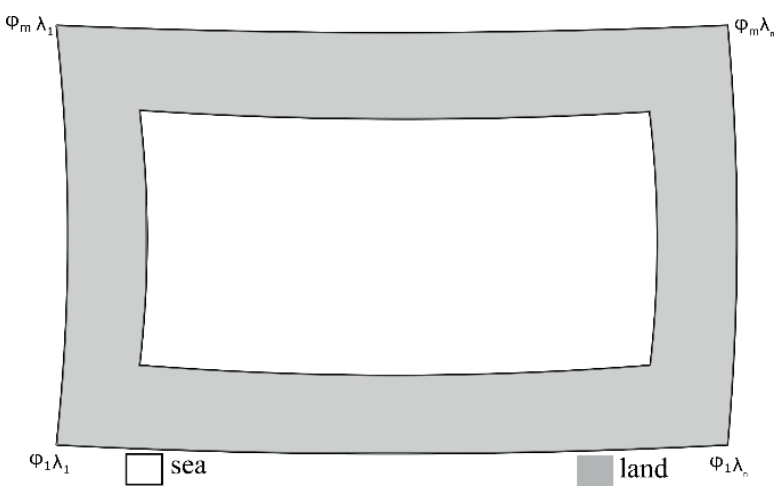

Fig. 2. A fragment of the real marine environment

For the given granularity, a grid of intersection points between horizontal and vertical curves was created as formula (1).

$$
Z=\frac{\left(\varphi_{\max }-\varphi_{\min }\right) \times\left(\lambda_{\max }-\lambda_{\min }\right)}{m \times n}
$$

where:

$m$ - the number of horizontal curves, and $n$ the number of vertical curves of the analysed grid

$\varphi_{\max }\left(\lambda_{\max }\right), \varphi_{\min }\left(\lambda_{\min }\right)$ - the minimum and maximum latitude (longitude).

$\varphi_{\text {min }}=\min \left\{\varphi_{i}, i=1,2, . ., m\right\}, \lambda_{\text {min }}=\min \left\{\lambda_{i}, i=1,2, . ., n\right\}, \varphi_{\text {max }}=$ $\max \left\{\varphi_{i}, i=1,2, . ., m\right\}, \lambda_{\text {max }}=\max \left\{\lambda_{i}, i=1,2, . ., n\right\}$.

Fig. 2 shows a simplified representation of a section of the real area. With the help of the grid used, the sections of the real area are replaced by a set of points $P_{i j}$, set at regular intervals and determined by the appropriate geographical coordinates: latitude $\varphi i$ and longitude $\lambda i$, i.e.

$$
P_{i j}=P\left(\varphi_{i}, \lambda_{j}\right)
$$

$i=1,2, \ldots, m ; j=1,2, \ldots, n$

where:

$\varphi_{i}$ - latitude value

$\lambda_{j}$ - longitude value

In the obtained discrete model, each geographical position from the real area is represented by an approximate, interpolated point from the set of points $P_{i j} \in P$ (Fig. 3). The grid of points consists of both navigable and non-navigable points, and navigable and non-navigable areas retain the same granularity. The choice of granularity may depend on the dynamics of the marine environment conditions or the required accuracy of the route description. The author changes the granularity of the mesh in the context of the ship's approach to hazardous areas in another article 17. Each point $P_{k}=P_{i j}$ has information on hydrometeorological data specifying the changing conditions of the marine environment at the moment $t$.

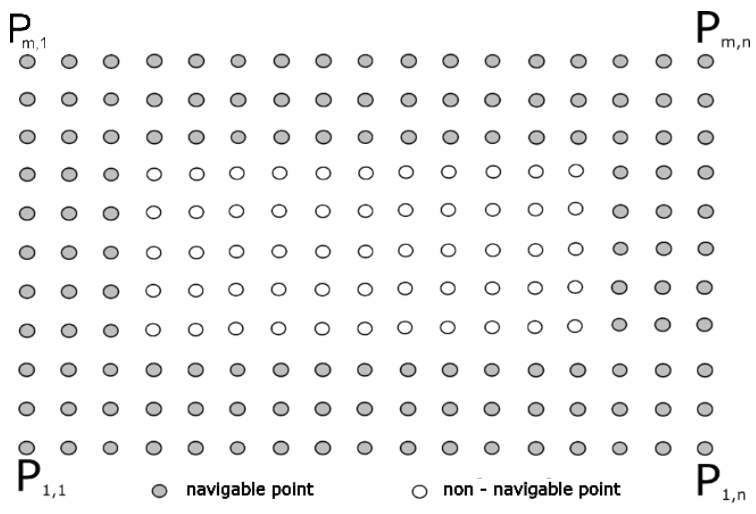

Fig. 3. Navigable and non-navigable points grid

\section{DESCRIPTION OF THE PROPERTIES OF A SAILING SHIP AND MANOEUVRING RULES}

The course change in the real marine environment is continuous, which means that one can choose any course if it meets the safety requirements. In the presented discrete sailing model, the selection of a specific navigation route is possible only if it is possible to connect the current point with the next point of travel, where both belong to the navigable zone. In this discrete model, it is also assumed that the ship's movement takes place only according to the proposed sailing rules, i.e. in accordance with the accepted number of allowed sailing directions $\in\{8,16,32\}$. 

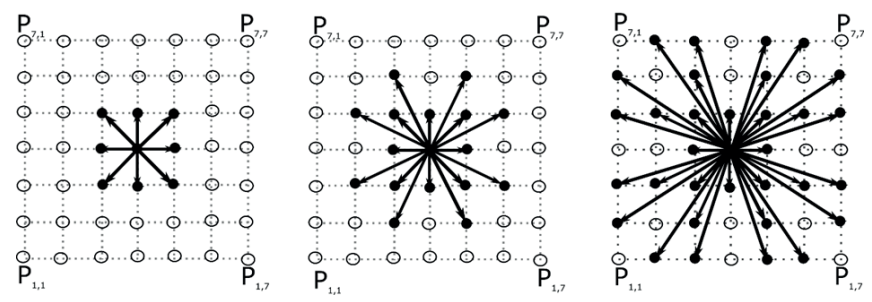

Fig. 4. Variants of permissible sailing directions $\{8,16,32\}$

The selection of the permissible number of sailing directions depends on the assumed accuracy of route planning. The higher the number, the higher the accuracy; however, this can result in longer tacks. Considering the current point $P_{k}$ in the navigable area, we can consider all possibilities of choosing the next point $\mathrm{P}_{1}$. The combination of points $P_{k}$ and $P_{l}$ is called the segment. The total route is a path that contains at least one segment. Thus, the entire route of a sailing vessel can be described by means of a set of consecutive sequences of points according to formula (3).

$$
\text { Route }=<P_{k_{1}}, P_{k_{2}}, \ldots, P_{k_{9}}>
$$

where:

$k_{i}$ - marks the next point belonging to this route, $\mathrm{i}=1,2, \ldots, \mathrm{L}$ $L$ - is the number of all route points

Each point $P_{k}$, where $k \epsilon(1,2, \ldots, m \bullet n)$, represents a specific geographical position and changing environmental conditions. On each segment of the route, additional parameters are also determined, which depend on the subsequent route points $P_{k_{i}}$, where i $\epsilon(1,2, \ldots, \mathrm{L})$. They are as follows: direction of movement from point $P_{k_{i}}$ to point $P_{k_{i+1}}$; length of segment from point $P_{k_{i}}$, to point $P_{k_{i+1}}$; time of the ship's passage after the section from $P_{k_{i}}$ to point $P_{k_{i+1}}$.

Variants of permissible sailing directions are shown in Fig. 4. The length of the segment from point $P_{k_{i}}$ to point $P_{k_{i+1}}$ is determined as the actual distance between these points, described by the relevant geographical coordinates. The crossing time, in turn, depends on the speed of the sailing vessel moving along this section. The vector $\overrightarrow{P_{k_{l}} P_{k_{l+1}}}$ between two points $P_{k_{i}}$ and $P_{k_{i+1}}$ has a certain direction, which is defined as the angle between this vector and the north direction. It is designated as $\alpha_{i, i+1}$, which is shown in Fig. 5.

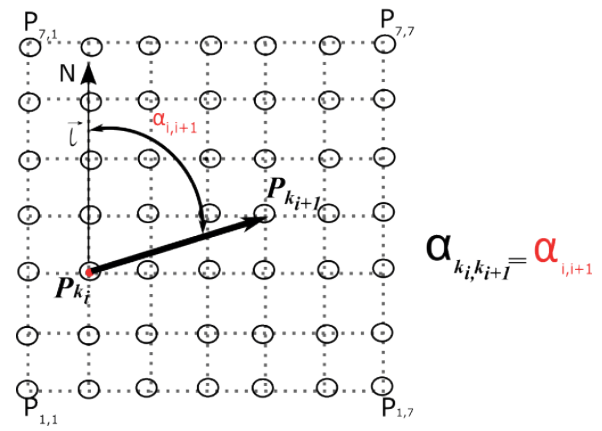

Fig. 5. Method of determining the direction of movement from point to point

As already mentioned, the length of the segment from point $P_{k_{i}}$ to point $P_{k_{i+1}}$ is denoted as $d\left(P_{k_{i}}, P_{k_{i+1}}\right)$ and we calculate it according to the following formula (4).

$d\left(P_{k_{i}}, P_{k_{i+1}}\right)=\sqrt{+\left(\left(\lambda_{k_{i}}-\lambda_{k_{i+1}}\right) \cdot \cos \left(\left(\varphi_{k_{i}}+\varphi_{k_{i+1}}\right) / 2\right)\right)^{2}}$

Each point $P_{k}$ has its geographical position $\varphi_{k}$ and $\lambda_{k}$. The length of the section between two points is measured in nautical miles (Nm). It is assumed that $1 \mathrm{Nm}$ is $1852 \mathrm{~m}$. When determining the length of the section, the navigational deviation was taken into account. The passage time of the ship after the segment is denoted by $t\left(P_{k_{i}}, P_{k_{i+1}}\right)$ and using formula (5).

$$
t\left(\mathrm{P}_{\mathrm{k}_{\mathrm{i}}}, \mathrm{P}_{\mathrm{k}_{\mathrm{i}+1}}\right)=\frac{\mathrm{d}\left(\mathrm{P}_{\mathrm{k}_{\mathrm{i}}} \mathrm{P}_{\mathrm{k}_{\mathrm{i}+1}}\right)}{v\left(\mathrm{P}_{\mathrm{k}_{\mathrm{i}}}, \mathrm{P}_{\mathrm{k}_{\mathrm{i}+1}}\right)}
$$

where:

$v\left(P_{k_{i}}, P_{k_{i+1}}\right)$ - segment passage speed from $P_{k_{i}}$ to $P_{k_{i+1}}$, expressed in knots.

The ship speed is estimated using the ship's polar characteristics, which are different for each ship and developed experimentally by its designers or manufacturers. It shows the relationship between the speed of the ship and the angle of attack of the wind at a certain speed. As Fig. 6 (b) shows, not all directions of movement are acceptable due to the efficiency of the sail wing. Typically, estimates of the speed characteristics of a sailing vessel by VPP-type programs are presented for calm water.

a)

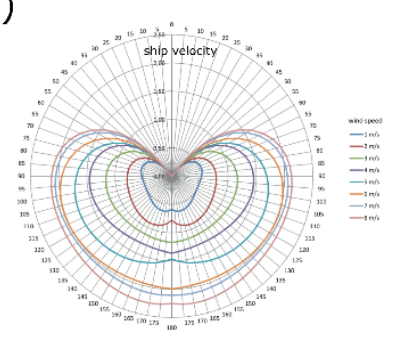

Fig. 6. a) Polar characteristics of the sailing vessel and b) illustration of permitted and prohibited directions

During the passage of the segment from point $P_{k_{i}}$ to point $P_{k_{i+1}}$, the ship's heel determined by the function heel $\left(P_{k_{i}}, P_{k_{i+1}}\right)$ is included. The expected value of heel for specific parameters and a specific choice of direction of movement from point $P_{k_{i}}$ to point $P_{k_{i+1}}$ is determined by formula (6).

$\operatorname{heel}\left(\mathrm{P}_{\mathrm{k}_{\mathrm{i}}}, \mathrm{P}_{\mathrm{k}_{\mathrm{i}+1}}\right)=\vartheta\left(\overrightarrow{\mathrm{W}}_{\mathrm{k}_{\mathrm{i}}}(\mathrm{t}), \alpha_{\mathrm{i}, \mathrm{i}+1}\right)=\vartheta\left(\mathrm{w}_{\mathrm{k}_{\mathrm{i}}}(\mathrm{t}), \beta_{\mathrm{i}, \mathrm{i}+1}(\mathrm{t})\right)$

where:

$\alpha_{i, i+1}$ - course of ship from point $P_{k_{i}}$ to point $P_{k_{i+1}}$

$\beta_{i, i+1}$ - angle of attack of wind on the vessel flowing from point $P_{k_{i}}$ to point $P_{k_{i+1}}$ 
Function $\vartheta\left(w_{k_{i+1}}(t), \beta_{i,+1}(t)\right)$ predicts the ship's heel based on its polar characteristics, wind speed $w_{k_{i+1}}(t)$ and angle of attack of wind on the vessel flowing $\beta_{i, i+1}(t)$.

\section{USER REQUIREMENTS AND CRITERIA}

Depending on the nature of the trip and the requirements of the watercraft user, different initial assumptions and tasks to be performed may be specified. These differ in the case of the owner of a commercial unit, the captain of the sailing vessel, the team of the sailing yacht participating in an ocean regatta, or the person managing the unmanned vessel. For this reason, the route with the shortest lead time is not always the only desired result of using the optimisation method. Important route selection criteria can also include a feeling of comfort (for passenger ships, as well as recreational yachts), minimal consumption of inventory (for a commercial unit), a sense of security (for beginner sailors), or finding the longest route without repetitions (for monitoring an area). In view of the wide variety of expectations of the stakeholders of the navigation, the priority of navigation is to choose the optimal route for the vessel user. In the article, based on a review of the literature, the author's own experience and expert opinions, five categories of users (U1, U2, U3, U4, U5) were distinguished, presenting different scenarios of the preferences of potential users of sailing vessels. U1 are participants of recreational cruises, attached to comfort, determined by the conditions of travel and ensuring safety. $\mathrm{U} 2$ are people seeking extreme sensations, assuming reduced safety restrictions and deciding to choose extreme sailing conditions. U3 are beginner sailors who care about mastering the art of sailing with security. U4 are the controllers of unmanned sailing ships who seek to ensure that they reach their destination safely. U5 are the participants in the regatta, who want to complete the route in the shortest possible time in well-recognised sailing conditions while maintaining moderate safety.

User preferences translate into criteria and restrictions in mapping the route. The following five travel selection criteria were adopted (K1, K2, K3, K4, K5).

$\mathrm{K} 1$ means getting the shortest travel time from a given start point to the destination. $\mathrm{K} 2$ is a choice of favourable travel conditions (good weather, no waves). K3 is to ensure the safety of travel through the precision of manoeuvres performed (turns and tilts, not exceeding the set values). K4 is to achieve travel comfort, which means reaching the destination in a given time and ensuring insurance manoeuvres, described by values much lower than the limit ones. $\mathrm{K} 5$ is to take risky decisions resulting from certain premises, exceeding the permissible capacity of the ship or sailing conditions.

It is possible to formulate links between categories of users and the adopted criteria, as presented in Table 1.
Tab. 1. User categories and route selection criteria

\begin{tabular}{|c|c|c|c|c|c|}
\hline User categories & K1 & K2 & K3 & K4 & K5 \\
\hline $\mathrm{U} 1$ & & + & + & + & \\
\hline $\mathrm{U} 2$ & + & & & & + \\
\hline $\mathrm{U} 3$ & & + & + & & \\
\hline $\mathrm{U} 4$ & & + & & + & \\
\hline $\mathrm{U} 5$ & + & & + & & + \\
\hline
\end{tabular}

When calculating the route in accordance with the assumed criteria, it is necessary to take into account certain restrictions for each user category. This approach brings the result of the route calculation method closer to the user's requirements. Five types of restrictions were adopted (O1, O2, O3, O4, O5). $\mathrm{O} 1$ is the permissible number of manoeuvres during a journey, where each manoeuvre is associated with time delay and discomfort. $\mathrm{O} 2$ is the permissible angle of change of the ship's course, ensuring its safe performance. $\mathrm{O} 3$ is the allowable number of tack changes (and heels resulting from this), related to comfort. $\mathrm{O} 4$ is the permissible roll value that indicates the presence of a hazard. O5 is the permissible angle of the ship's attack on the wind, also determining the safety of sailing.

By bringing the method results closer to the user's expectations, in addition to the limit, configuration parameters have been introduced. Configuration parameters include P1, P2 and P3. P1 is the choice of the number of traffic directions allowed, ensuring greater accuracy and affecting travel comfort. P2 is the number of currently considered weather forecasts affecting the reliability of the received route and maximising the instantaneous achievements. P3 is a change in the grain size of the sailing area to ensure the accuracy of the manoeuvre.

Tab. 2. Restrictions and configuration parameters

\begin{tabular}{|c|c|c|c|c|c|c|c|c|}
\hline User category $\begin{array}{r}\text { Restriction and } \\
\text { configuration } \\
\text { parameter }\end{array}$ & 01 & 02 & 03 & 04 & 05 & $P 1$ & $P 2$ & P3 \\
\hline U1 & $\bullet$ & • & ... & $\bullet$ & $\bullet$ & • & • & • \\
\hline U2 & & . & & • & • & •• & & .• \\
\hline U3 & & • & • & • & $\bullet$ & • & $\bullet$ & • \\
\hline $\mathrm{U} 4$ & $\cdot$ & $\cdot$ & $\cdot$ & $\bullet$ & $\bullet$ & • & $\cdot$ & $\cdot$ \\
\hline U5 & • & • & • & $\cdot$ & $\bullet$ & $\cdots$ & $\cdots$ & $\bullet$ \\
\hline
\end{tabular}

Of course, other parameters may affect the implementation of the route in accordance with the criteria of the trip, but their inclusion does not require changes in the proposed method for selecting the optimal route within the accepted categories of users. The restrictions and configuration parameters necessary for the implementation of the route in accordance with these categories of users are shown in Table 2.

The dots indicate the significance of a given restriction or configuration parameter for the implementation of a route consistent with a particular user category. Because the user category is related to the implementation of various goals, the number of dots determines the priority, taking into account 
the relevant restrictions and configuration parameters. Table 2 shows that for users of category U1, the most important is the $\mathrm{O} 3$ limit, while O1, O4 and $\mathrm{O} 5$ are very important. For category $\mathrm{U} 2$, the parameters $\mathrm{P} 1$ and $\mathrm{P} 3$ are very important, while the restrictions $\mathrm{O} 1, \mathrm{O} 3$ and $\mathrm{P} 2$ are immaterial. For category $\mathrm{U} 3$, the $\mathrm{O} 5$ limitation and the $\mathrm{P} 2$ parameter are very important, while the $\mathrm{O} 1$ limitation is insignificant. For category $\mathrm{U} 4, \mathrm{O} 4$ and $\mathrm{O} 5$ are very important, while the others are less important. For category U5, the most important are parameters $\mathrm{P} 1$ and $\mathrm{P} 2, \mathrm{P} 3$ and $\mathrm{O} 5$ are very important, while the others are less important. Table 2 indicates the role that these restrictions and configuration parameters play in choosing a route that meets the expectations of users of a particular category.

\section{PROPOSED GOAL FUNCTION}

It was assumed that the route depends on human decisions, taking into account existing or anticipated situations. Human decisions can be taken into account by using configuration parameters $\left(P_{1}, P_{2}, P_{3}\right)$ and restrictions introduced in advance $\left(\mathrm{O}_{1}, \mathrm{O}_{2}, \ldots, \mathrm{O}_{3}\right)$. The situations encountered in turn describe the discomfort coefficients $\left(\gamma_{1}, \ldots, \gamma_{6}\right)$. The basic categories of travel discomfort for a sailing vessel include too abrupt manoeuvres of the vessel, too much rocking of the vessel, too strong heel of the vessel and too large and too small wind angles. Any discomfort encountered affects the end result of the goal function. The route will therefore be a function of these quantities (7).

Route $=\mathrm{f}_{\mathrm{g}}\left(\mathrm{O}_{1}, \mathrm{O}_{2}, \ldots, \mathrm{O}_{5}, \mathrm{P}_{1}, \mathrm{P}_{2}, \mathrm{P}_{3}, \gamma_{1}, \ldots, \gamma_{6}\right)$

Each $i$-th discomfort can last $\tau$ (i) time, as a result of which it increases the value of the goal function. Taking into account the adopted restrictions and configuration parameters, it can be considered that the goal function is as shown below (8).

$$
\mathrm{f}_{\mathrm{g}}=\mathrm{t}(\text { Route })+\sum_{\mathrm{p}=1}^{5} \tau_{\mathrm{p}} \cdot \gamma_{\mathrm{p}}
$$

where:

$\tau_{p}$ - total cost associated with taking the $p$-th discomfort into account.

Restrictions and configuration parameters and travel discomfort are input arguments for the objective function that affect its result. It is worth noting that $\mathrm{O} 1$ and $\mathrm{O} 3$ are restrictions that increase the cost of passing between route points. For example, in Tab. 2 "O1 = •" marks the additional cost of the function during each course change (the greater the change in course, the greater the cost). What is more, "O1 = •." and "O1 = •.." mean a greater cost for each degree of change in course. On the other hand, O2, O4 and O5 do not allow certain connections between points in this discrete model due to limitations: as to the maximum value of the course change, as to the maximum roll, or the maximum wind attack. In these cases, the greater the number of dots, the greater the number of inaccessible connections between points in this discrete model. As another input argument of function, the configuration parameters P1, P2, P3 increase or decrease the number of points or connections in this discrete model. With these parameters, we can increase the accuracy of the route we are looking for, but this also increases the necessary computing power.

When searching for the optimal route, we may encounter travel discomfort (if it is included as a function input parameter), which causes additional costs for the destination function. The value of the objective function is also influenced by travel discomfort. During the search for the optimal route, we encounter one of the discomforts of travel, which causes additional costs for the objective function.

Simulation studies were limited to the following categories of discomfort: violent manoeuvres, strong roll, and excessive or small angles of wind attack during travel.

\section{SAILING ASSISTANCE APPLICATION AS A TEST ENVIRONMENT}

Simulation tests are carried out in a specially prepared test environment, called the Sailing Assistance application. The application consists of three layers (Data, Routing Algorithm, Route Visualisation), which allows independent development of each layer.

\begin{tabular}{|c|c|c|}
\hline \multicolumn{3}{|c|}{ Route Visualisation } \\
\hline \multicolumn{3}{|c|}{ Routing Algorithm } \\
\hline Optimisation criteria & User requirements & Restrictions \\
\hline \multicolumn{3}{|c|}{ Data } \\
\hline $\begin{array}{c}\text { Ship } \\
\text { characteristics }\end{array}$ & $\begin{array}{l}\text { Shipping } \\
\text { conditions }\end{array}$ & $\begin{array}{c}\text { Sailing } \\
\text { area }\end{array}$ \\
\hline
\end{tabular}

Fig. 7. Sailing assistance application

The user interface of the Sailing Assistance application enables the configuration of parameters such as: selection of the number of allowable directions of movement $(8,16,32)$; selection of the starting point $\mathrm{P}_{\mathrm{s}}$ and ending $\mathrm{P}_{\mathrm{F}}$ in a defined rectangular area; determination of granularity, density of $\mathrm{P}_{\mathrm{k}}$ points (low, high); selection of a sailing vessel from the list of available vessels (Conrad, Oceania); taking into account the comfort factor when calculating the route (yes / no); taking into account the additional time needed to change the course (0s / deg, 1s / deg, ..., 16s / deg); taking into account the limit of the value of a one-off exchange rate change $(20,30,40$, ..., 360); taking into account the minimum wind angle (20, $30, \ldots, 60)$. 


\section{RESULTS}

During the simulation, the preferences of 4 categories of users were taken into account: recreational cruises, seeking extreme sensations, beginner sailors, and steering unmanned sailing ships. For these users, the parameter settings in the Sailing Assistance application are given in Table 2. The simulation tests were carried out in three series.
Each series includes a different start and end position. During the simulation, constant wind conditions were assumed for the entire area covered by the algorithm analysis. Changing wind conditions are included in another article by the author [17]. The results of optimal routes according to the criteria of specific categories of users are shown in Table 3, while route visualisations are presented in Figs. 9-20.

Tab. 1. Results of the simulation study

Stable navigation conditions: wind direction N, wind strength $12 \mathrm{~m} / \mathrm{s}$.

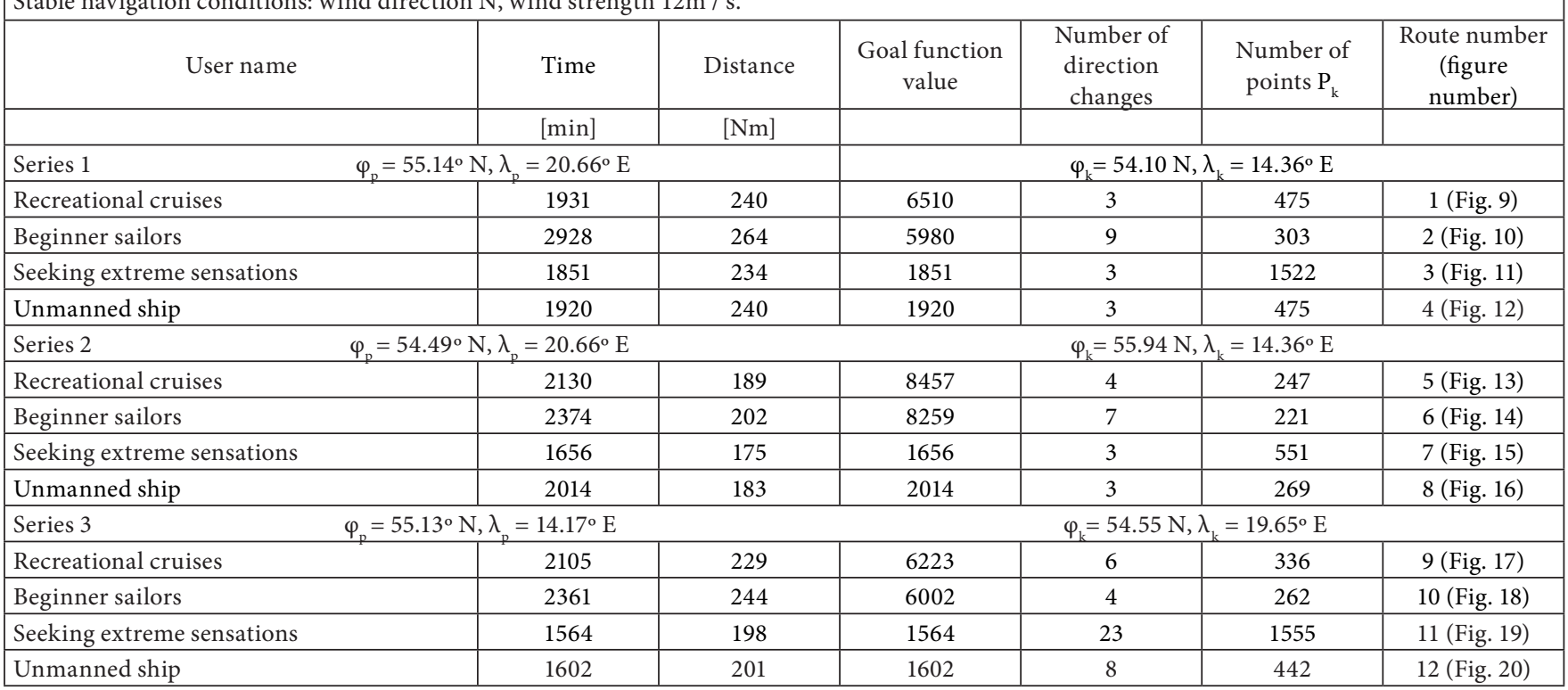

\section{Simulations for Series 1.}

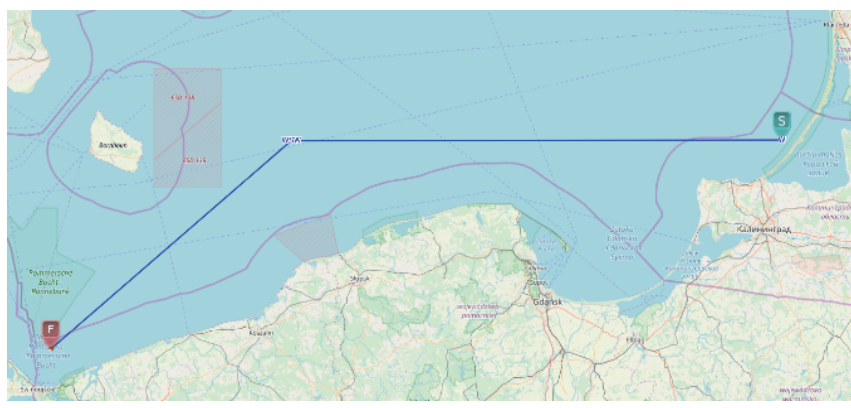

Fig. 8. Route number 1, recreational cruises

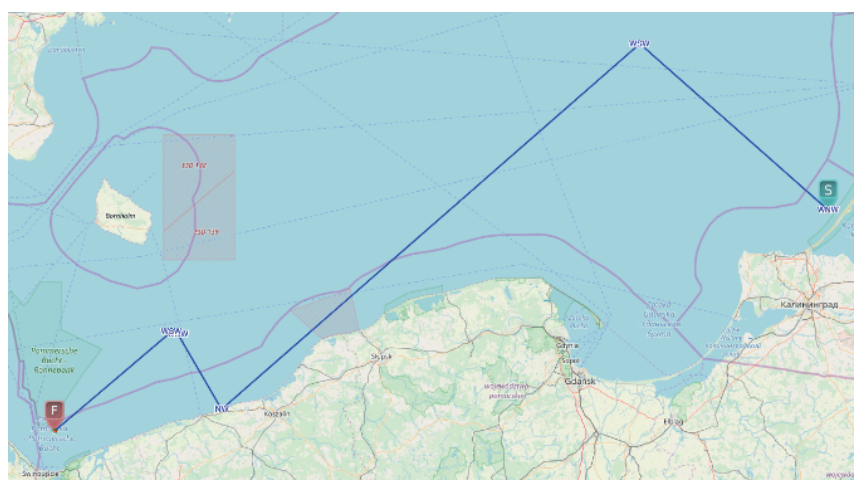

Fig. 9. Route number 2, beginner sailors

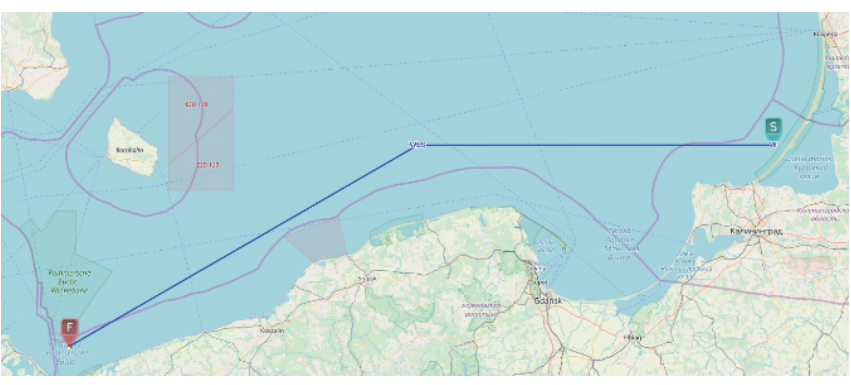

Fig. 10. Route number 3, seeking extreme sensations

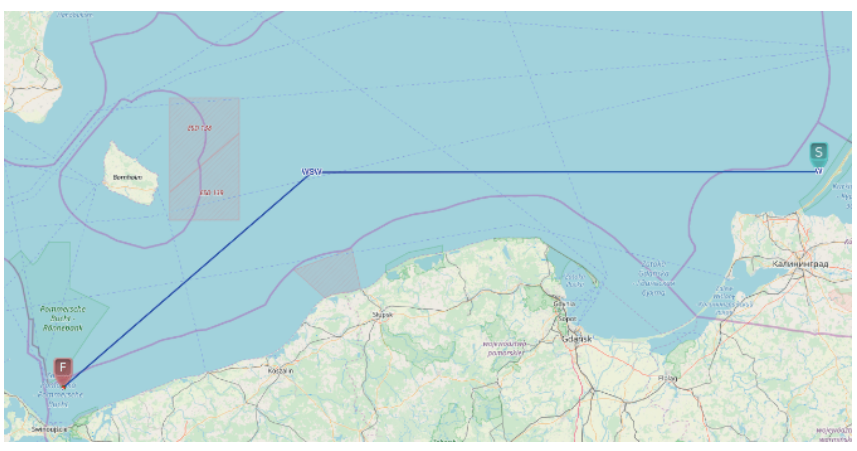

Fig. 11. Route number 4, steering unmanned sailing ships 
Simulations for Series 2.

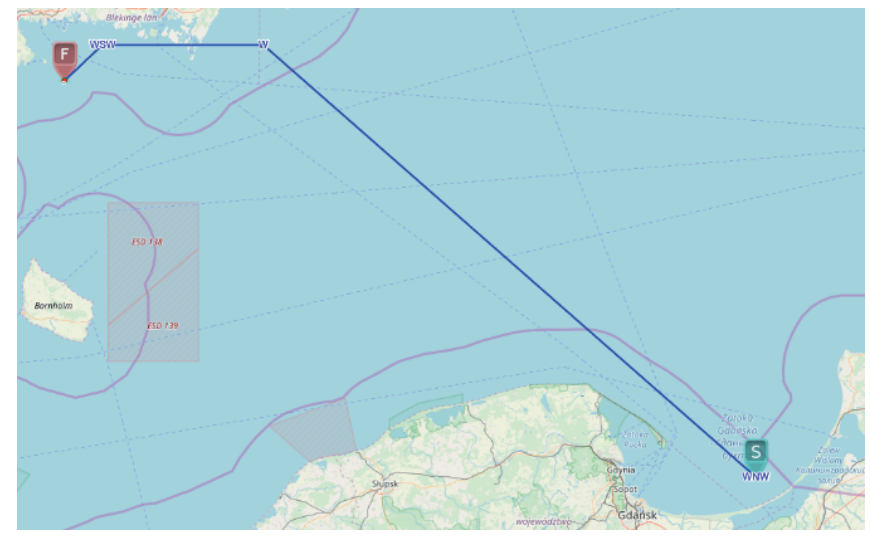

Fig. 12. Route number 5, recreational cruises

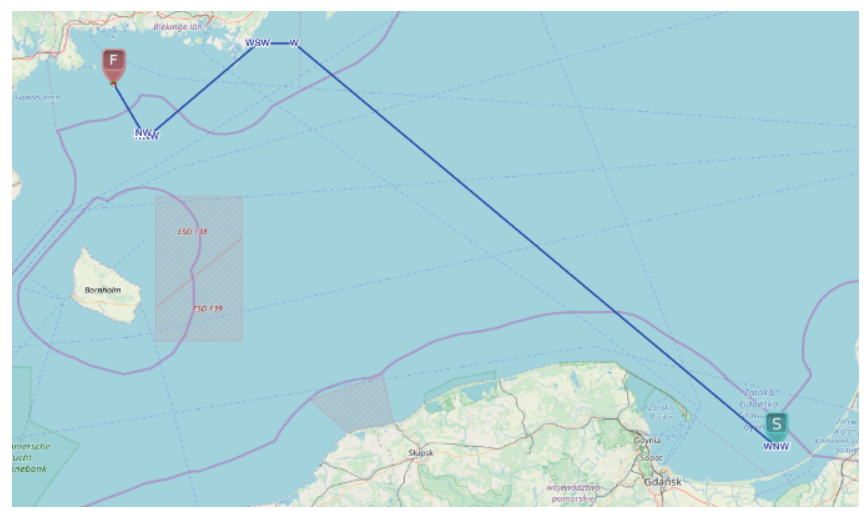

Fig. 13. Route number 6, beginner sailors

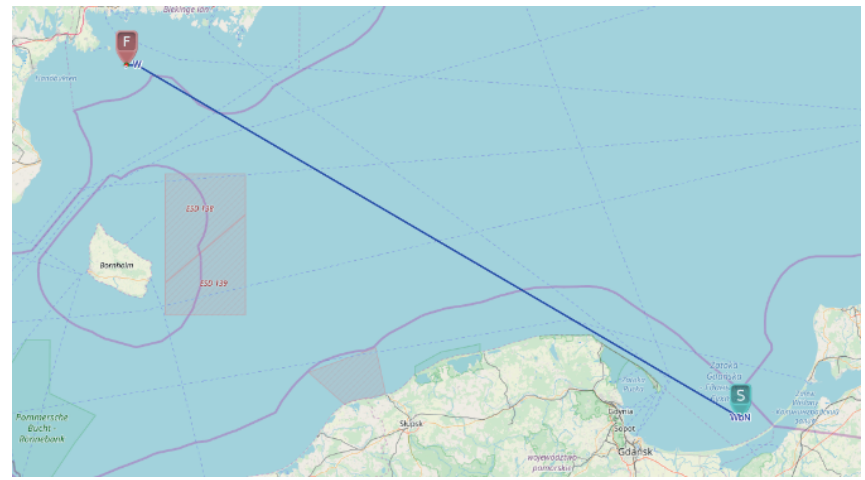

Fig. 14. Route number 7 , seeking extreme sensations

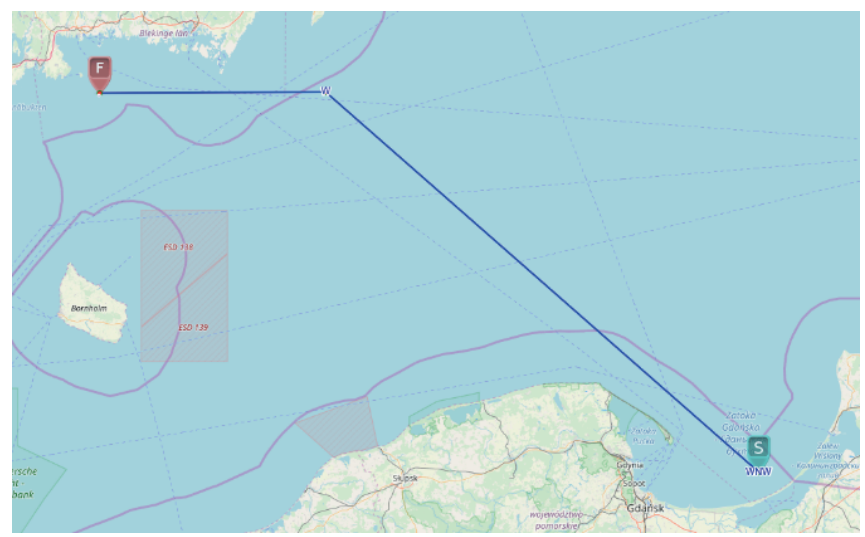

Fig. 15. Route number 8, steering unmanned sailing ships

\section{Simulations for Series 3.}

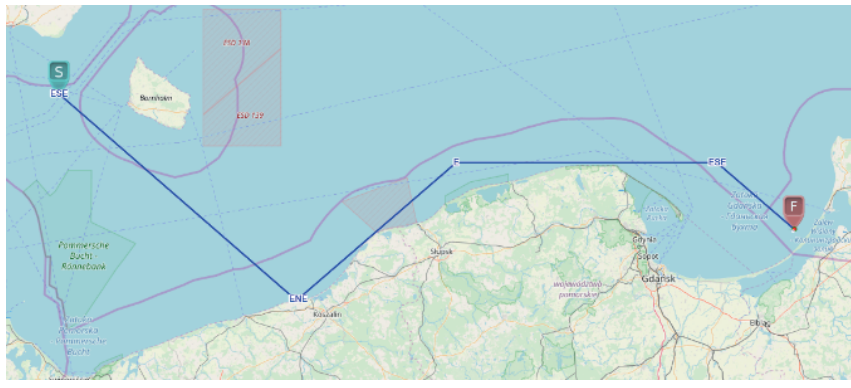

Fig. 16. Route number 9, recreational cruises

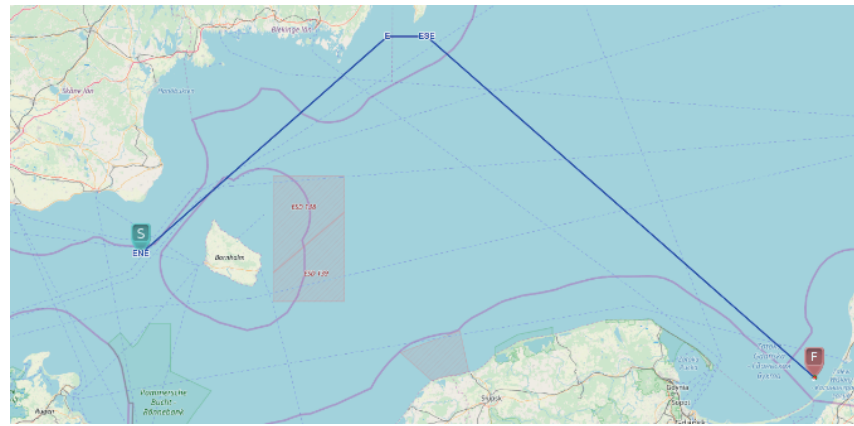

Fig. 17. Route number10, beginner sailors

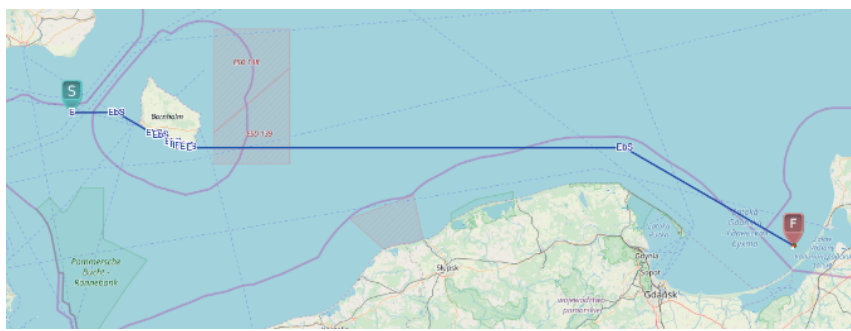

Fig. 18. Route number 11, seeking extreme sensations

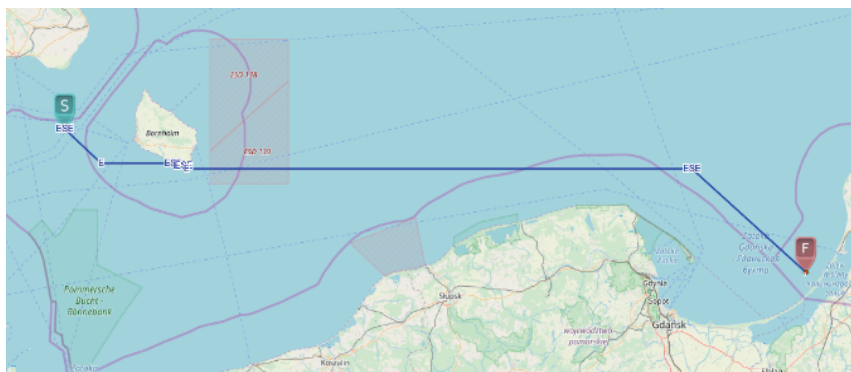

Fig. 19. Route number 12, steering unmanned sailing ships

\section{DISCUSSION}

Table 3 presents the results of users as well as their restrictions and configuration parameters. The largest values in a given series are marked in red font. The lowest values in a given series are marked in bold. As Table 3 shows, in the research series carried out, seeking extreme sensations obtained the lowest values of travel time, distance and goal function values. For this user, the optimal route search 
algorithm included the fewest restrictions (only 3 dots for O1, $\mathrm{O} 4$ and O5). This user needed the most $P_{k}$ points to complete the route. This results from the fact that it uses the highest accuracy of route search (4 dots for parameters P1 and P3). The highest values of travel time, distance and goal function values were obtained by beginner sailors, and recreational cruises, because these users had the most restrictions.

Tab. 3. User restrictions and configuration parameters and results possible. This user selects favourable travel conditions, and his route is devoid of turns and inclinations exceeding the set values.

Users seeking extreme sensations, in turn, count on the maximum speed of sailing, while accepting a lower level of safety. During the test, this user obtained the fastest time and the shortest route. It was not important for him to limit the number of manoeuvres, or the number of changes in

\begin{tabular}{|c|c|c|c|c|c|c|c|c|c|c|c|c|c|c|}
\hline $\begin{array}{r}\begin{array}{r}\text { Restriction } \\
\text { and configuration } \\
\text { parameter }\end{array} \\
\text { User } \\
\text { category }\end{array}$ & 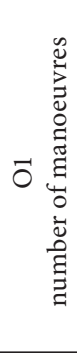 & 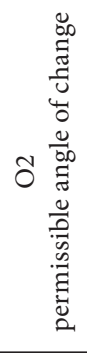 & 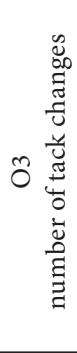 & 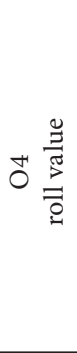 & 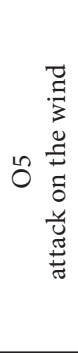 & 口. & 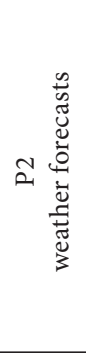 & 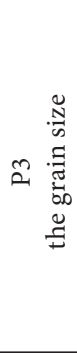 & & $\stackrel{\Xi}{\Xi}$ & 艺 & $\frac{\stackrel{2}{3}}{3}$ & 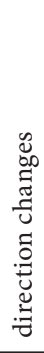 & $\begin{array}{l}0^{-1} \\
0 \\
. \\
0 \\
0 \\
0\end{array}$ \\
\hline Recreational cruises & $\bullet$ & $\bullet$ & $\bullet \bullet$ & $\bullet$ & $\bullet$ & $\bullet$ & $\bullet$ & $\bullet$ & $\begin{array}{l}\text { Series1 } \\
\text { Series2 } \\
\text { Series3 }\end{array}$ & $\begin{array}{l}1931 \\
2130 \\
2105\end{array}$ & $\begin{array}{l}240 \\
189 \\
229\end{array}$ & $\begin{array}{l}6510 \\
8475 \\
6223\end{array}$ & $\begin{array}{l}3 \\
4 \\
6\end{array}$ & $\begin{array}{l}475 \\
247 \\
336\end{array}$ \\
\hline Beginner sailors & & $\bullet$ & $\bullet$ & $\bullet$ & $\bullet$ & $\bullet$ & $\bullet$ & $\bullet$ & $\begin{array}{l}\text { Series1 } \\
\text { Series2 } \\
\text { Series3 }\end{array}$ & $\begin{array}{l}2928 \\
2374 \\
2361\end{array}$ & $\begin{array}{l}264 \\
202 \\
244\end{array}$ & $\begin{array}{l}5980 \\
8259 \\
6002\end{array}$ & $\begin{array}{l}9 \\
7 \\
4\end{array}$ & $\begin{array}{l}303 \\
221 \\
262\end{array}$ \\
\hline $\begin{array}{l}\text { Seeking extreme } \\
\text { sensations }\end{array}$ & & $\bullet$ & & $\bullet$ & $\bullet$ & $\bullet$ & & $\bullet \bullet$ & $\begin{array}{l}\text { Series1 } \\
\text { Series2 } \\
\text { Series3 }\end{array}$ & $\begin{array}{l}1851 \\
1656 \\
1564 \\
\end{array}$ & $\begin{array}{l}234 \\
175 \\
198 \\
\end{array}$ & $\begin{array}{l}1851 \\
1656 \\
1564 \\
\end{array}$ & $\begin{array}{c}3 \\
3 \\
23 \\
\end{array}$ & $\begin{array}{c}1522 \\
551 \\
1555 \\
\end{array}$ \\
\hline Unmanned ship & $\bullet$ & $\bullet$ & • & $\bullet$ & $\bullet$ & $\bullet$ & $\bullet$ & $\bullet$ & $\begin{array}{l}\text { Series1 } \\
\text { Series2 } \\
\text { Series3 }\end{array}$ & $\begin{array}{l}1920 \\
2014 \\
1602\end{array}$ & $\begin{array}{l}240 \\
183 \\
201\end{array}$ & $\begin{array}{l}1920 \\
2014 \\
1602\end{array}$ & $\begin{array}{l}\mathbf{3} \\
\mathbf{3} \\
8\end{array}$ & $\begin{array}{l}475 \\
269 \\
442\end{array}$ \\
\hline
\end{tabular}

\section{CONCLUSIONS}

The simulation study presented was based on the multicriteria method of selecting the optimal route discussed for different categories of users. The simulation results allow one to observe visible differences in both the route and its time and length. It should be emphasised that travel time was not always the most important criterion. We observe the minimisation of travel time in the case of users seeking extreme experiences, and this is a factor much less important in the case of other categories of users. This is due to different user preferences.

For cruise users, travel comfort is as important as the minimum travel time, as it has a large effect on the overall satisfaction of passengers. In the study presented, this recreational cruiser made the fewest turns and avoided unnecessary roll when sailing, which extended its travel time.

The beginner sailor in all series obtained the longest travel time from all categories of users. He made the most course changes in order to avoid large course changes and run with a large roll. For this user, a route with a minimum travel time was therefore not the priority. In this case, the most important criterion for route planning was the safety resulting from favorable navigation conditions and as few manoeuvres as inclination during travel, which significantly affects the comfort of travel.

As for the unmanned sailing ship, it is important to maintain its navigation capability from the beginning to the end of the route. Great emphasis is placed on safety. This means that the ship must reach its destination while maintaining a high level of security. During the study, this user made relatively few turns and did not choose the route with the shortest travel time. For this category of users, the route is determined by restrictions specifying the permissible amount of heel and the permissible angle of the ship's wind attack.

The presented study was to determine the optimal route for various categories of users by adopting a multi-criteria approach. Depending on different user requirements, the method allows different sequences of travel points to be obtained for identical input data. In each case, the proposed route is adapted to the user's navigation preferences, which is proof of both the usability and universality of the adopted method.

\section{REFERENCES}

1. Dębski, R.: An adaptive multi-spline refinement algorithm in simulation based sailboat trajectory optimization using onboard multi-core computer systems, Int. J. Appl. Math. Comput. Sci. 26 (2016) 351-365. 
2. Goldberg, A. V: Point-to-Point Shortest Path Algorithms with Preprocessing, in: LNCS 4362 - SOFSEM 2007 Theory Pract. Comput. Sci., 2007.

3. Krata, P., J. Szłapczyńska: Weather Hazard Avoidance in Modeling Safety of Motor-Driven Ship for Multicriteria Weather Routing, TransNav. 6 (2012) 71-78.

4. Ladany, S.P., O. Levi: Search for optimal sailing policy, Eur. J. Oper. Res. 260 (2017) 222-231.

5. Lisowski, J.: The Sensitivity of State Differential Game Vessel Traffic Model, Polish Marit. Res. 23 (2016) 14-18.

6. Mannarini, G., G. Coppini, P. Oddo, N. Pinardi: A Prototype of Ship Routing Decision Support System for an Operational Oceanographic Service, TransNav, Int. J. Mar. Navig. Saf. Sea Transp. 7 (2013) 53-59.

7. Maury, M.F.: The Physical Geography of the Sea and Its Meteorology, Harper Bros, New York, 1855.

8. Neumann, T.: The shortest path problem with uncertain information in transport networks, in: Commun. Comput. Inf. Sci., Springer, Cham, 2016: pp. 475-486.

9. Szlapczynska, J., R. Szlapczynski: Preference-based evolutionary multi-objective optimization in ship weather routing, Appl. Soft Comput. 84 (2019) 105742.

10. Szlapczynski, R.: Evolutionary Sets of Safe Ship Trajectories : Evaluation of Individuals, Int. J. Mar. Navig. Saf. Sea Transp. 6 (2012) 345-353.

11. Szlapczynski, R.: Evolutionary Planning of Safe Ship Tracks in Restricted Visibility, J. Navig. 68 (2015) 39-51.

12. Szlapczynski, R., J. Szlapczynska: A method of determining and visualizing safe motion parameters of a ship navigating in restricted waters, Ocean Eng. 129 (2017) 363-373.

13. Tagliaferri, F., I.M. Viola: A real-time strategy-decision program for sailing yacht races, (2017).

14. Vettor, R., C.G. Soares: Development of a ship weather routing system, Ocean Eng. 123 (2016) 1-14.

15. Wrobel, K., P. Krata, J. Montewka, T. Hinz: Towards the Development of a Risk Model for Unmanned Vessels Design and Operations, TransNav, Int. J. Mar. Navig. Saf. Sea Transp. 10 (2016) 267-274.

16. Zyczkowska, K.: Uniqueness or Uniformity - Studies of Media Architecture, IOP Conf. Ser. Mater. Sci. Eng. 471 (2019) 072040.
17. Życzkowski, M.: Sailing Vessel Routing Considering Safety Zone and Penalty Time for Altering Course, TransNav, Int. J. Mar. Navig. Saf. Sea Transp. 11 (2017) 49-54.

18. Życzkowski, M.: Method of routing ships sailing in dedicated environment, Annu. Navig. 24 (2017) 147-159.

19. Życzkowski, M., P. Krata, R. Szłapczyński: Multi-objective weather routing of sailboats considering wave resistance, Polish Marit. Res. 25 (2018) 4-12.

20. Życzkowski, M., R. Szłapczyński: Multi-objective weather routing of sailing vessels, Polish Marit. Res. 24 (2017) 10-17.

\section{CONTACT WITH THE AUTHOR}

\author{
Marcin Życzkowski \\ e-mail:marzyczk@pg.edu.pl
}

Gdańsk University of Technology

11/12 Gabriela Narutowicza Street 80-233 Gdańsk

Poland 